\title{
The Current Status of Continuous Flow Left Ventricular Assist Devices
}

\author{
Babar B Chaudhri* \\ Department of Cardiovascular and Thoracic Surgery, Intrathoracic Transplantation, Mechanical Circulatory Support and Heart Failure, \\ India
}

*Corresponding author: Babar B Chaudhri, Department of Cardiovascular and Thoracic Surgery, Intrathoracic Transplantation, Mechanical Circulatory Support and Heart Failure, India

\begin{abstract}
In this review, we hope to give a perspective of the new realities of cardiac mechanical circulatory assist devices. New iterations of devices are providing greater durability and freedom of complications. Work is near to provide internal batteries and transcutaneous energy transfer systems for completely implantable systems, avoiding the need for an externalized drive line.
\end{abstract}

Keywords: Heart Failure; Transplantation; Mechanical Circulatory Support

\section{Introduction}

In patients with severe heart failure, cardiac transplantation has been shown to provide considerable benefit. Since 1967, in excess of 88,000 total heart transplants have been performed and 1-year survival is $81 \%$, the annual mortality is $4 \%$ per year thereafter. The supply of donor hearts is incredibly limited and much research has focused on mechanical means of improving myocardial function, and several such left ventricular assist devices (LVADs) have been developed through the National Institutes of Health artificialheart program. Several devices have been previously approved by the Food and Drug Administration as bridging therapy to transplantation, though none have been studied as long-term alternatives to transplantation. The Randomized Evaluation of Mechanical Assistance for the Treatment of Congestive Heart Failure (REMATCH) [1] trial explored whether a specific type of LVAD (a previous generation pulsatile device), when used in the long-term, would reduce mortality (Figure 1). The survival following severe heart failure was extremely poor in the optimally medically treated group in this trial (defined as End-stage heart failure was defined as New York Heart Association (NYHA) class IV symptoms for at least 90 days, left ventricular ejection fraction (LVEF) $<25 \%$, peak oxygen consumption $<12 \mathrm{~mL} / \mathrm{kg} / \mathrm{min}$ or continued need for intravenous inotropes for symptomatic hypotension).
In the optimally medically treated control arm of the Randomized Evaluation of Mechanical Assistance for the Treatment of Congestive Heart Failure (REMATCH) trial [1] which evaluated an externalized pulsation ventricular assist device, survival at one year was $28 \%$ and $6 \%$ at two years, underlying the poor prognosis of this clinical entity (Figure 1). Driving the need for mechanical circulatory support (MCS) is the relative paucity of donors and the unmet need for orthotopic heart transplantation in the general population. There has also been an increase in the number of patients who require mechanical circulatory support (MCS) as a bridge to transplantation [2]. This has been driven, particularly in the UK by limitation of the number of hearts for donation, and also to buy time on the transplant waiting list. This is due to an increase in the numbers of non-heart beating donors (DCDs), whereby retrieval takes place in a circulation arrested donor, and the increased survival of head injury patients and those with intracranial bleeds who are treated by a decompressive craniotomy, reducing the pool of donors who have raised intracranial pressure and who have coned, resulting in brain stem death. The net result is a retrieval rate for heart transplantation of around $19 \%$. The risk of having preformed antibodies directed against the donor heart (sensitised patients) is increasingly likely and is particularly 
challenging as it may increase the risk of rejection and allograft vasculopathy. There has also been an increase in the number of patients requiring MCS as a bridge to transplantation [3]. This allows many severely ill adults and paediatric patients to survive until a suitable donor heart is available. Patients with MCS are at increased risk for rejection, infection, stroke, and bleeding. The need for transfusions also increases the risk of pre-sensitization [3-5]. Survival at 1 and 5 years is decreased in patients requiring MCS prior to transplantation, but still higher than $80 \%$ and $70 \%$, respectively (ISHLT database) [2].

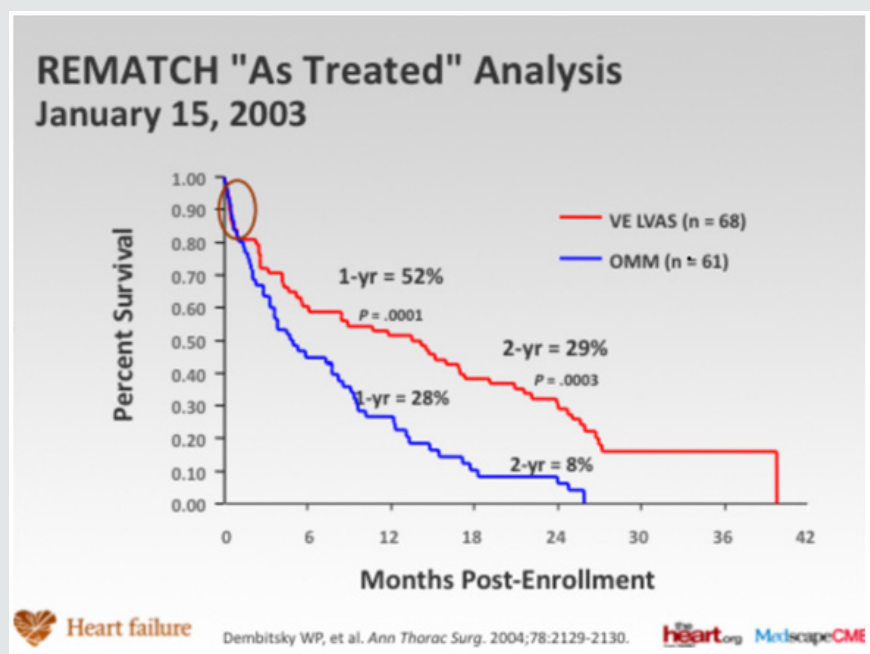

Figure 1: Randomized Evaluation of Mechanical Assistance for the Treatment of Congestive Heart Failure (REMATCH) trial (Rose et al N Engl J Med 2001; 345:1435-1443).

\section{Advances in Donor Allocation and Selection}

Recipient criteria for heart transplantation include, severe symptoms despite maximal medical management, the absence of reversible or surgically amenable heart disease, and where estimated 1-year survival is less than 50\% [6]. An estimate of functional capacity in ambulatory patients can be best quantified by measurement of peak $\mathrm{O}_{2}$ consumption ( $\mathrm{VO}_{2} \mathrm{max}$ ). Patients with low
V02max ( $<12 \mathrm{ml} / \mathrm{min} / \mathrm{kg}$ ) have high mortality even if treated with beta blockers and transplantation should be considered for these patients. In addition, heart failure prognosis scores to estimate survival, such as the Heart Failure Severity Score may be used. This calculates a survival probability on the basis of the presence of ischaemic cardiomyopathy, resting heart rate, left ventricular ejection fraction, mean blood pressure, interventricular conduction delay, $\mathrm{VO}_{2}$ max and serum sodium concentration [7].

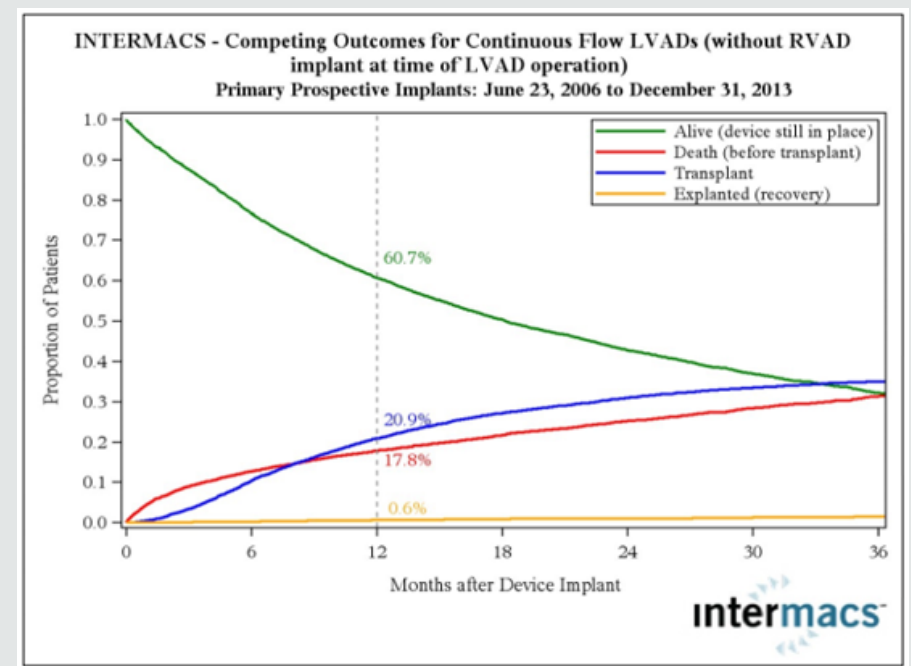

Figure 2: Competing outcomes for continuous flow LVADS (82\% survival at 1 year, intention to treat).

Transplantation eligibility is always considered with regard to risk factors, especially, pulmonary hypertension (Figure 2). Right heart catheterization must be performed in all potential candidates for heart transplantation in order to quantify pulmonary vascular resistance [7]. Right heart failure is a substantial cause of mortality. Right ventricular failure is likely when post implant pulmonary artery pressures exceed $50 \mathrm{mmHg}$. Patients with chronic heart failure may develop pulmonary hypertension due to elevated 
left ventricular end diastolic pressure with elevated left atrial and pulmonary venous pressures. This is a reactive form of pulmonary hypertension and may fall when the cardiac output is increased with inotropes or unloaded with nitrate infusions [7]. The transpulmonary gradient is calculated by subtracting the left atrial filling pressure from the mean pulmonary artery pressure. A fixed transpulmonary gradient in excess of $14 \mathrm{mmHg}$ is associated with greatly elevated risk, and thus this cut off is used in the UK [8]. In such patients a destination therapy strategy may be used with continuous flow LVADS.

\section{Mechanical Circulatory Assist Devices}

In recent years, the use of MCS device in treating patients with end-stage heart disease has increased significantly, as bridge to transplantation and as destination therapy for transplant ineligible candidates. This increase is based on the accumulated experience with new second-generation continuous-flow devices which show significant improvements in survival, functional capacity and quality of life $[9,10]$. On the basis of the Heart Mate II Registry experience (1300 patients), guidelines for the clinical management of patients treated with continuous-flow devices have been published [11]. Risk scoring systems, such as the Seattle Heart Failure Model [12] and the Cumulative Risk Score for 90-Day in-Hospital Mortality [13] and the Destination Therapy Risk Score have been investigated to stratify patients who might benefit from LVAD support [14].

Right ventricle failure is a leading cause of morbidity and death after LVAD implant (incidence of about 35\%), and can be very difficult to predict $[15,16]$. Various means to assess right ventricle function both pre- and postoperatively have been assessed (10). Right ventricular failure risk scores have been created that stratify the risk of right ventricular failure (RVFRS) and death after LVAD implantation (Figure 3). One such RVFRS found independent predictors of right ventricular failure to include vasopressor requirement, aspartate aminotransferase $>80 \mathrm{IU} / \mathrm{L}$, bilirubin $>2.0 \mathrm{mg} / \mathrm{dL}$ and creatinine $>2.3 \mathrm{mg} / \mathrm{dL}$ [15]. Another study developed a score to predict RVAD need after LVAD placement, which included factors of cardiac index, right ventricular stroke work index, severe preoperative right ventricular dysfunction, creatinine, previous cardiac surgery and systolic blood pressure [16]. More recently the presence of severe TR and a tricuspid annulus of $>43 \mathrm{~mm}$ and right ventricular sphericity have been proposed as predictive of occult RV failure and need for biventricular support. The Interagency Registry for Mechanically Assisted Circulatory Support (INTERMACS) registry, which follows all long-term MCS systems in the United States, has defined patient profiles that can help identify risks associated with the timing of implant [17]. In the future, the INTERMACS patient profile would be a useful tool to improve management and outcomes of patients who need VAD implant and unify criteria for future clinical trials and devices (Figure 4). As more LVAD patients are listed for heart transplant, a competition has occurred for organs between stable LVAD supported registrants and less stable registrants listed UNOS status $1 \mathrm{~A}$ or $1 \mathrm{~B}$ (the highest categories and most at risk if not urgently transplanted). A recent study found that stable LVAD patients had significantly less 30-day risk of events compared to other status $1 \mathrm{~A}$ patients concluding that allowance of 30 days of elective status $1 \mathrm{~A}$ time should not be allocated to stable registrants with implanted LVADs [18]. As VAD technology improves, further revisions to the allocation system will need to be recommended.

\section{Study Design}

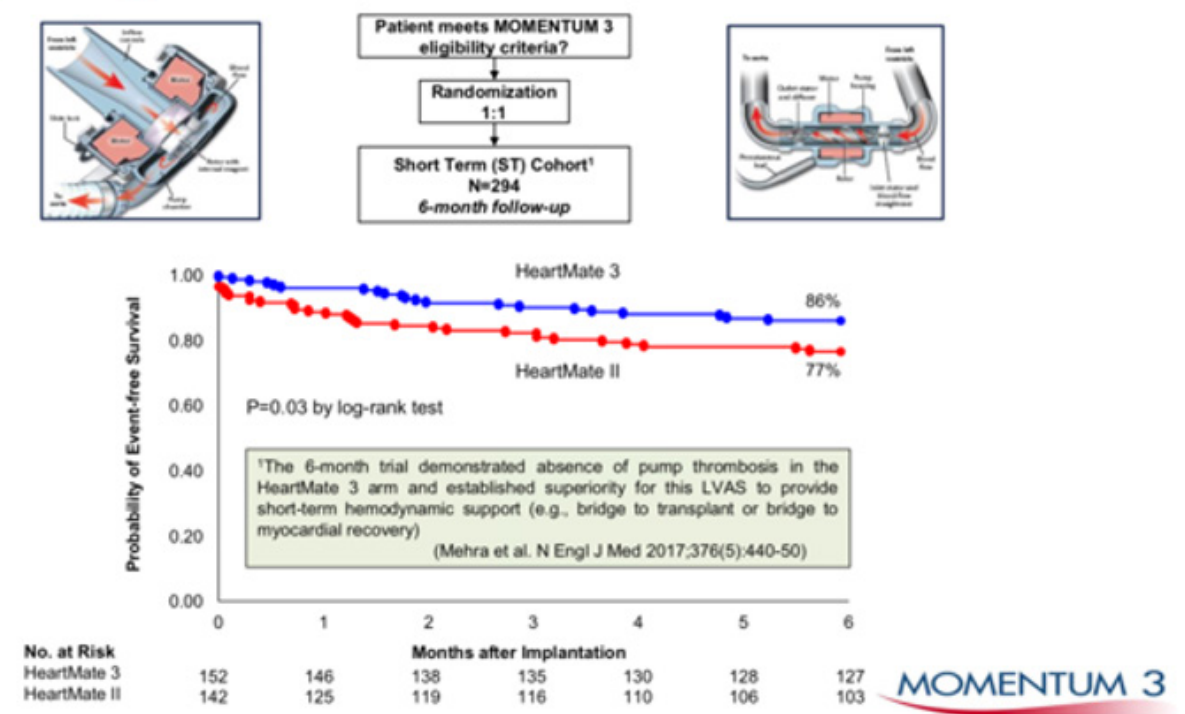

Figure 3: Heartmate 3, the latest centrifugal blood pump in comparison to Heartmate II an axial flow pump. Superior event free survival is seen with HM 3. 


\section{HeartMate 3 LVAS \\ Primary Endpoint Component 3 \\ Freedom from Reoperation to Replace or Remove Pump}

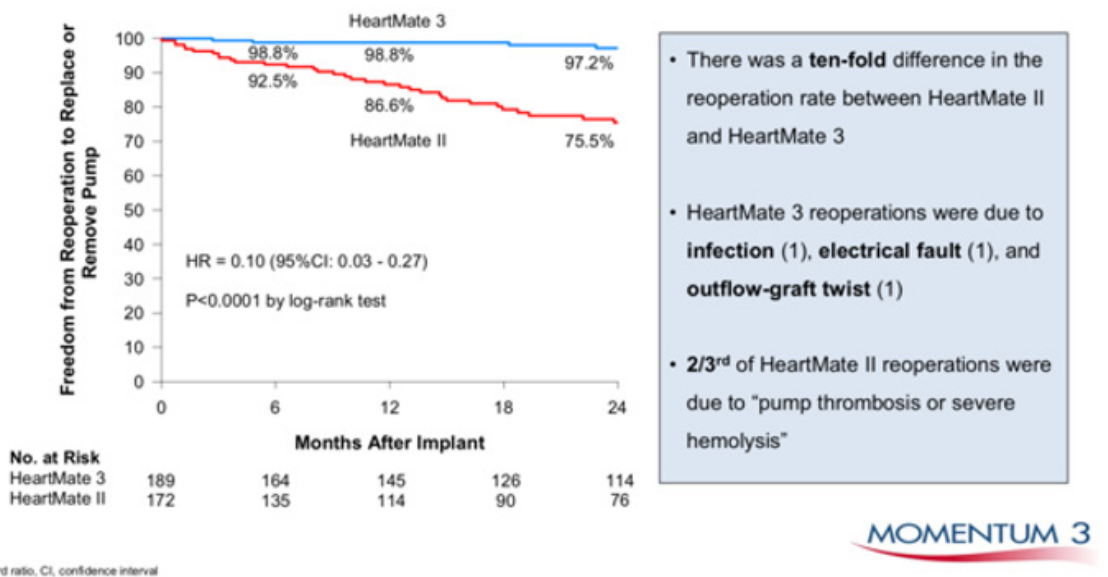

Figure 4: Heart-mate 3 vs Heartmate II comparison of event free survival.

\section{INTERMACS Profile and Description and Timescale to MCS}

a) "Crashing and burning"-critical cardiogenic shock. Within hours

b) "Progressive decline"-inotrope dependence with continuing deterioration. Within a few days

c) "Stable but inotrope dependent"-describes clinical stability on mild-to-moderate doses of intravenous inotropes (patients stable on temporary circulatory support without inotropes are within this profile). Within a few weeks

d) "Recurrent advanced heart failure"- "recurrent" rather than "refractory" decompensation. Within weeks to months

e) "Exertion intolerant"-describes patients who are comfortable at rest but are exercise intolerant. Variable

f) "Exertion limited"-describes a patient who is able to do some mild activity but fatigue results within a few minutes of any meaningful physical exertion. Variable

g) "Advanced NYHA III"-describes patients who are clinically stable with a reasonable level of comfortable activity, despite history of previous decompensation that is not recent. Not a candidate for MCS

INTERMACS = Interagency Registry for Mechanically Assisted Circulatory Support; MCS = mechanical circulatory support; NYHA = New York Heart Association .

\section{Primary Endpoint Component 3 Freedom from Reoperation to Replace or Remove Pump}
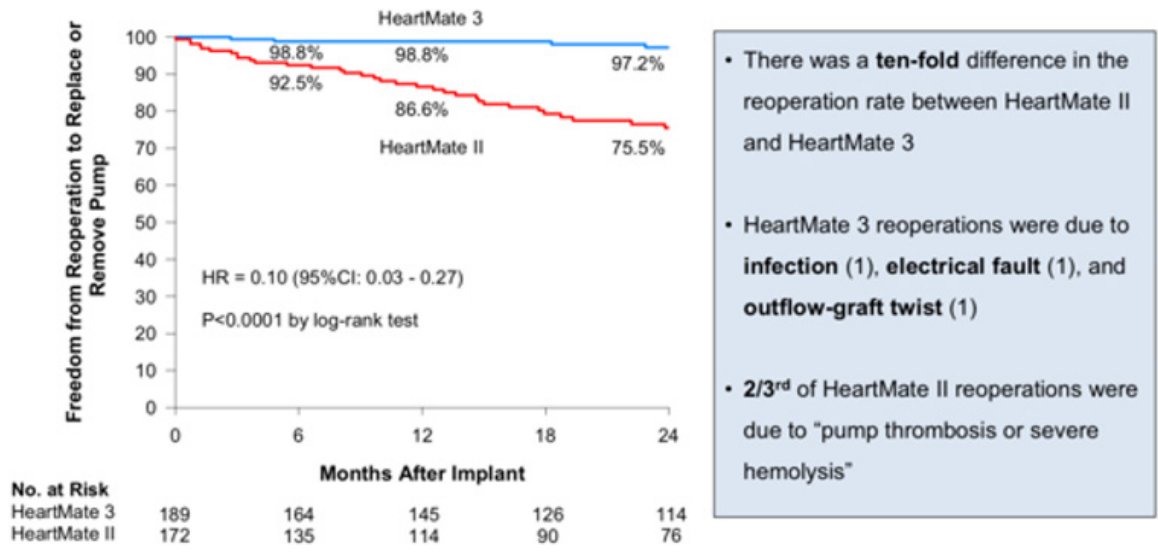

MOMENTUM 3

Figure 5: Durability of HM 3 vs HM II, freedom from pump replacement due to pump thrombosis or haemolysis. 
Temporary MCS are available that can be implanted quickly and simply to normalise cardiac output in patients with severe acutely decompensated heart failure. The CentriMag [19], Tandem Heart [20], Impella [21] and Circulite [22]. Clinical trials suggest that treatment of temporary VADs does not necessarily correlate with better survival, but merely comprise a component of treatment leading to recovery, upgrade to fully implantable systems as a bridge to transplant or destination therapy, or transplantation $[23,24]$. Device miniaturisation, without externalized drive-lines connecting the device to a console and longer endurance will be the future trend of mechanical design for long term support. Blood pumps with magnetically levitated rotors has shown satisfactory 1-year survival [25]. The smaller size and weight of the continuousflow devices has allowed an extension of the new VADs into smaller patients. Fully wireless resonant coupling power sources are currently undergoing evaluation, which if successful will greatly reduce the incidence of drive line infections (Figure 5), which is the weakest point of the technology of current fully implantable systems. There is some evidence that fully implantable systems will be available in the near future to greatly improve the quality of life and to reduce the frequency of severe infections with continuous flow LVADS
Many recent studies have focused on the reversed molecular and cellular alterations, such as improved $\beta$-adrenergic responses and decreased calcium-regulating gene expression (Figure 6), in patients using LVAD as a bridge to recovery therapy [26]. Functional recovery has been observed in a subset of heart failure patients $[26,27]$. Recently, a clinical trial using clenbuterol ( $\beta-2$ agonist and anabolic agent) and LVAD in refractory non-ischemic heart failure patients, reported recovery of heart function in $60 \%$ of patients $(n=20)$ with non-ischemic cardiomyopathy that allows the pump to be explanted (Harefield Recovery Protocol Study for Patients with Refractory Chronic Heart Failure, HARPS) [28]. LVAD therapy is associated with decreased collagen turnover and crosslinking and increased tissue angiotensin II. LVAD combined with angiotensinconverting enzyme inhibition results in decreased tissue angiotensin II and collagen cross-linking, normalizes left ventricular end-diastolic pressure volume relationships and is associated with modestly higher rates of bridge to recovery [29]. Other adjunctive treatments including other medications, cell or gene therapy with over expression of SERCA2a might in conjunction with VAD support provide a meaningful alternative therapy in patients with severe heart disease [30].

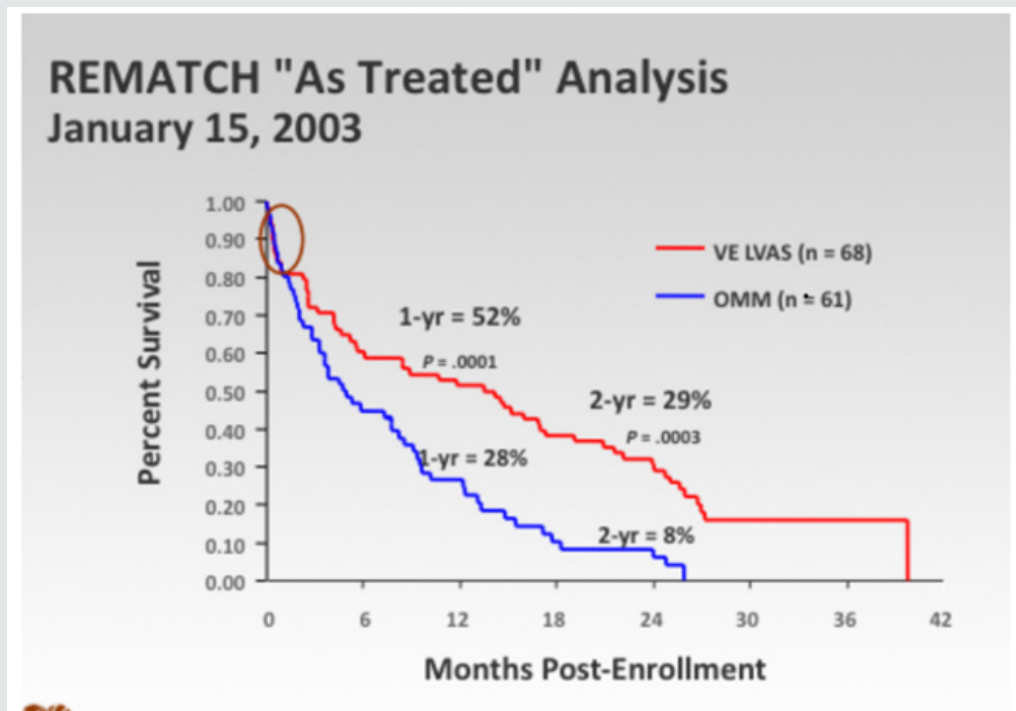

Heart failure

Dembitsky WP, et al. Ann Tharac Surg. 2004;78:2129-2130.

hểarton ModscapecME

Figure 6.

\section{Conclusion}

Heart transplantation is associated with excellent long-term outcomes and is the gold standard solution for intractable end stage heart failure in eligible patients. What limits its impact, overall, is the limited availability of donor organs. The development of ventricular assist devices has mitigated against this, to some extent. Subsequent device iterations with further miniaturisation and continuous flow have resulted in effective bridge to transplant solutions. The presence of an externalized drive line exposes the
VAD recipient to infections, however, which may precipitate urgent listing for heart transplant in the bridge to transplant candidate and may limit the life span of the destination therapy candidate. Fully implantable driveline free systems will definitely enhance the utility of these systems in these settings. As our knowledge of molecular medicine increases, manipulation of key proteins implicated in the pathophysiology of heart failure such as SERCA2a may allow some recovery of the myocardium in patients with heart failure to the extent that transplantation may be deferred or the LVAD explanted [31-35]. 


\section{References}

1. Rose EA, Gelijns AC, Moskowitz AJ, Heitjan DF, Stevenson LW (2001) Randomized Evaluation of Mechanical Assistance for the Treatment of Congestive Heart Failure Study. Long-term use of a left ventricular assist device for end-stage heart failure. N Engl J Med 345: 1435-1443.

2. Lund LH, Edwards LB, Kucheryavaya AY, Dipchand A (2013) Registry of the International Society for Heart and Lung Transplantation: Thirtieeth official adult heart transplant report-2013. J Heart Lung Transplant 32(10): 951-964

3. Hunt SA (2007) Mechanical circulatory support: new data, old problems. Circulation 116(5): 461-462.

4. Kerman RH (2007) Understanding the sensitised patient. Heart Fail Clin 3(1): $1-9$

5. Valantine H (2004) Cardiac allograft vasculopathy after heart transplantation: risk factors and management. J Heart Lung Transplant 23(5): S187-S193.

6. Aaronson KD, Schwartz JS, Chen TM, Wong KL, Goin JE, et al. (1997) Development and prospective validation of a clinical index to predict survival in ambulatory patients referred for cardiac transplant evaluation. Circulation 95(12): 2660e7.

7. Mehra MR, Kobashigawa J, Starling R (2006) Listing criteria for heart transplantation: International Society for Heart and Lung Transplantation guidelines for the care of cardiac transplant candidates. J Heart Lung Transplant 25(9): 1024-1042.

8. Christie JD, Edwards LB, Kucheryavaya AY (2010) The Registry of the International Society for Heart and Lung Transplantation: twenty seventh official adult lung and heart and lung transplant report. J Heart Lung Transplant 29: 1104-1118.

9. Miller LW, Pagani FD, Russell SD (2007) Use of a continuous-flow device in patients awaiting heart transplantation. N Engl J Med 357(9): 885896.

10. Slaughter MS, Rogers JG, Milano CA (2009) Advanced heart failure treated with continuous-flow left ventricular assist device. N Engl J Med 361(23): 2241-2251.

11. Slaughter MS, Pagani FD, Rogers JG (2010) Clinical management of continuous-flow left ventricular assist devices in advanced heart failure. J Heart Lung Transplant 29(4 Suppl): S1-S39.

12. Levy WC, Mozaffarian D, Linker DT, Farrar DJ, Miller LW (2009) Can the Seattle heart failure model be used to risk-stratify heart failure patients for potential left ventricular assist device therapy? J Heart Lung Transplant 28(3): 231-236.

13. Lietz K, Long JW, Kfoury AG (2007) Outcomes of left ventricular assist device implantation as destination therapy in the post-REMATCH era: Implications for patient selection. Circulation 116: 497-505.

14. Teuteberg J, Ewald G, Adamson R (2012) Risk assessment for continuous flow left ventricular assist devices: Does the destination therapy risk score work? J Am Coll Cardiol 60(1): 44-51.

15. Matthews JC, Koelling TM, Pagani FD, Aaronson KD (2008) The right ventricular failure risk score. J Am Coll Cardiol 51: 2163-2172.

16. Fitzpatrick JR, Frederick JR, Hsu VM (2008) Risk score derived from preoperative data analysis predicts the need for biventricular mechanical circulatory support. J Heart Lung Transplant 27(12): 1286-1292.

17. Stevenson LW, Pagani FD, Young JB (2009) INTERMACS profiles of advanced heart failure: The current picture. J Heart Lung Transplant 28(6): 535-541.

18. Dardas T, Mokadam N, Pagani F, Aaronson K, Levy WC (2012) Transplant registrants with implanted left ventricular assist devices have insufficient risk to justify elective organ procurement and transplantation network status 1A time. J Am Coll Cardiol 60(1): 36-43.
19. John R, Long JW, Massey HT (2011) Outcomes of a multicenter trial of the Levitronix CentriMag ventricular assist system for short-term circulatory support. J Thorac Cardiovasc Surg 141(4): 932-939.

20. Kiernan MS, Krishnamurthy B, Kapur NK (2010) Percutaneous right ventricular assist via the internal jugular vein in cardiogenic shock complicating an acute inferior myocardial infarction. J Invasive Cardiol 22(2): E23-E26.

21. Granfeldt H, Hellgren L, Dellgren G (2009) Experience with the Impella recovery axial-flow system for acute heart failure at three cardiothoracic centers in Sweden. Scand Cardiovasc J 43: 233-239.

22. Klotz S, Meyns B, Simon A (2010) Partial mechanical long-term support with the CircuLite Synergy pump as bridge-to-transplant in congestive heart failure. Thorac Cardiovasc Surg 58(Suppl 2): S173-S178.

23. Seyfarth M, Sibbing D, Bauer I (2008) A randomized clinical trial to evaluate the safety and efficacy of a percutaneous left ventricular assist device versus intra-aortic balloon pumping for treatment of cardiogenic shock caused by myocardial infarction. J Am Coll Cardiol 52(19): 15841588 .

24. Cheng JM, den Uil CA, Hoeks SE (2009) Percutaneous left ventricular assist devices vs. intra-aortic balloon pump counterpulsation for treatment of cardiogenic shock: A meta-analysis of controlled trials. Eur Heart J 30(17): 2102-2108.

25. Wieselthaler GM, O Driscoll G, Jansz P, Khaghani A, Strueber M (2010) Initial clinical experience with a novel left ventricular assist device with a magnetically levitated rotor in a multi-institutional trial. J Heart Lung Transplant 29(11): 1218-1225.

26. Hall JL, Birks EJ, Grindle S (2007) Molecular signature of recovery following combination left ventricular assist device (LVAD) support and pharmacologic therapy. Eur Heart J 28(5): 613-627.

27. Hall JL, Fermin DR, Birks EJ (2011) Clinical, molecular, and genomic changes in response to a left ventricular assist device. J Am Coll Cardiol 57(6): 641-652.

28. Birks EJ, George RS, Hedger M (2011) Reversal of severe heart failure with a continuous-flow left ventricular assist device and pharmacologic therapy: A prospective study. Circulation 123(4): 381-390.

29. Butler CR, Jugdutt BI (2012) The paradox of left ventricular assist device unloading and myocardial recovery in end-stage dilated cardiomyopathy: Implications for heart failure in the elderly. Heart Fail Rev 17(4-5): 615-633.

30. Anastasiadis K, Antonitsis P, Argiriadou H (2011) Hybrid approach of ventricular assist device and autologous bone marrow stem cells implantation in end-stage ischemic heart failure enhances myocardial reperfusion. J Transl Med 9: 12.

31. Chaudhri BB, Del Monte F, Hajjar RJ, Harding SE (2002) Interaction between increased SERCA2a activity and beta -adrenoceptor stimulation in adult rabbit myocytes. Am J Physiol Heart Circ Physiol 283(6): H2450-

32. Chaudhri BB, del Monte F, Harding SE, Hajjar RJ (2004) Gene transfer in cardiac myocytes. Surg Clin North Am 84(1): 141-159.

33. Terracciano CM, Hardy J, Birks EJ, Khaghani A, Banner NR, et al. (2004) Clinical recovery from end-stage heart failure using left-ventricular assist device and pharmacological therapy correlates with increased sarcoplasmic reticulum calcium content but not with regression of cellular hypertrophy. Circulation 109(19): 2263-2265.

34. Kawase Y, Ly HQ, Prunier F (2008) Reversal of cardiac dysfunction after long-term expression of SERCA2a by gene transfer in a preclinical model of heart failure. J Am Coll Cardiol 51(11): 1112- 1119.

35. Investigation of the Safety and Feasibility of AAV1/SERCA2a Gene Transfer in Patients with Chronic Heart Failure and a Left Ventricular Assist Device (SERCA-LVAD). ClinicalTrials.gov Identifier: NCT00534703 
(C) (1) This work is licensed under Creative

To Submit Your Article Click Here: Submit Article

DOI: 10.32474/ACR.2019.01.000125

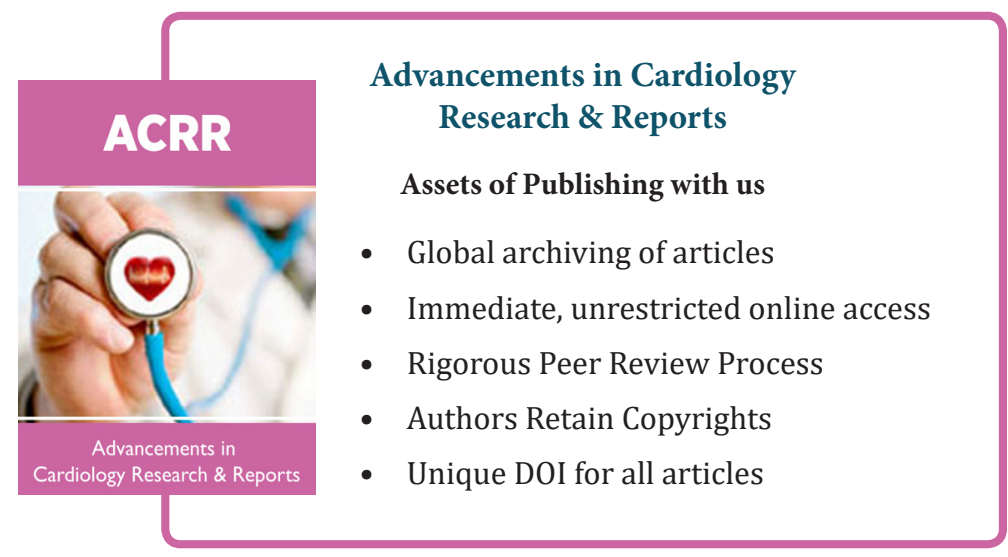

